\title{
Piezoelectric on Natural Fiber Reinforced Epoxy Composite for Wireless Energy Harvesting ${ }^{\dagger}$
}

\author{
Dounia El Fadlaoui ${ }^{1, *}$, Brahim Boubeker ${ }^{1}$, Mohamed Idiri ${ }^{1}$, Soukaina Essaket ${ }^{1}$ \\ 1 Laboratory of Engineering and Materials (LIMAT) / Faculty of Science Ben M'Sik, Hassan II University, Casablanca, \\ Morocco \\ * Correspondence: douniaaelfadlaoui@gmail.com; \\ $\dagger$ Presented at Materials Chemistry and Physics (Materials Chemistry 2020) - International e-Conference
}

Received: 16.09.2020; Revised: 20.09.2020; Accepted: 24.09.2020; Published: 27.09.2020

\begin{abstract}
Energy harvesting have a variety of application areas such as aircraft, automotive, medical .this energy provides a route for the realization of autonomous and self-powered low power electronic devices, for wireless sensor networks, it eliminates the need for wireless or replacement batteries. The purpose of this paper is to develop and improve the capacity of energy harvesting. In this study, an MFC harvesting elements were laid up with the Natural fiber/epoxy composites that will be fabricated prapag at the fabrication stage, and co-within an autoclave that can convert mechanical vibrations to electrical energy will study to supply power a wireless impedance sensor node. Finally, a series of experimental tests will be verified.
\end{abstract}

Keywords: energy harvesting; MFC; natural fiber; epoxy resin.

(C) 2020 by the authors. This article is an open-access article distributed under the terms and conditions of the Creative Commons Attribution (CC BY) license (https://creativecommons.org/licenses/by/4.0/).

\section{Funding}

This research received no external funding.

\section{Acknowledgments}

This research has no acknowledgments.

\section{Conflicts of Interest}

The authors declare no conflict of interest. 